\title{
Sudden infant death syndrome: are we any closer to identifying which infants will be affected?
}

This article was published in the following Dove Press journal:

Pediatric Health, Medicine and Therapeutics

14 March 2013

Number of times this article has been viewed

\author{
Tara L Ramirez \\ Michael H Malloy \\ Department of Pediatrics, The \\ University of Texas Medical Branch, \\ Galveston, TX, USA
}

\begin{abstract}
Sudden infant death syndrome is a complex and multifactoral process. The classification and definition of the syndrome has changed over time. As knowledge in the genetics of this complex syndrome continues to advance, additional causes of vulnerability have been found, but no single cause has yet been discovered. Over the last 40 years there have also been many advances in the identification of risk factors that make a given infant more vulnerable to succumbing to sudden infant death. There have also been great strides made in decreasing the number of infant deaths from this syndrome by modification of these risk factors, most notably with the initiation of the Back to Sleep campaign. With the initiation of the Safe to Sleep campaign there is hope that sudden infant death syndrome as a component of all sudden unexpected infant deaths can be further reduced.
\end{abstract}

Keywords: sudden infant death syndrome, sudden unexpected death of infancy, risk factors, sleep-related infant death, crib death, cot death

\section{Introduction}

Since sudden infant death syndrome (SIDS) was first defined 43 years ago there have been many changes to both the definition and classification of SIDS. There has also been a shift in the language used to describe sudden infant deaths. SIDS is now considered one type of sudden unexplained infant death (SUID) or sudden unexplained death of infancy. What causes SIDS deaths remains speculative. Are we any closer to identifying which infant will be affected? To better answer this question, the more recent definitions and current classification schemes of SIDS must be reviewed. This review will look at both intrinsic and extrinsic risk factors and how they are related to SIDS as well as how SIDS differs from other forms of sudden infant deaths.

\section{Definitions}

SIDS was first defined in 1969 as the sudden death of any infant or young child, which is unexpected by history and which, after a thorough postmortem examination, fails to demonstrate an adequate cause for death. ${ }^{1}$ There were problems with this definition and it lacked mention of the presumed onset of the death during sleep. There were initially no exclusion criteria and no discussion of the clinical features common to most cases. Investigation of the death scene/case history was not included in this definition. Despite this very general definition, many studies from all over the world began to report similar profiles of SIDS deaths. These included age distribution (peaking at 2-4 months), ${ }^{2,3}$ death discovered after or during sleep, seasonal distribution, association with minor illness, prematurity, and social disadvantage. ${ }^{1}$ There were similar physical findings
Correspondence: Michael H Malloy Department of Pediatrics, Division of Neonatology, University of Texas Medical Branch, 30I University Blvd, Galveston, TX 77555-0526, USA

Tel +I 4097722815

Email mmalloy@utmb.edu 
on autopsies performed on SIDS cases as well, including prominent intrathoracic petechiae, pulmonary congestion and edema, minor inflammatory infiltrates in the respiratory tract, fluid blood, and empty urinary bladders. ${ }^{1}$

The definition was refined in 1989 when the National Institute of Child Health and Human Development put together a group to better define SIDS. ${ }^{1}$ The revised definition, not published until 1991, stated that SIDS was "the sudden death of an infant under 1 year of age, which remains unexplained after a thorough case investigation, including the performance of a compete autopsy, examination of the death scene, and review of the clinical history." "This definition addresses the aspect of an age limit and emphasizes a review of the clinical history and examination of the death scene, which as mentioned above was felt to be redundant in the initial 1969 definition. $^{1}$

In 1992, Beckwith proposed adding classifications or stratifications to the working definition of SIDS. ${ }^{1}$ His proposal was not initially accepted..$^{5}$ However, in 2004, the CJ Foundation sponsored a meeting in which a panel of experts in the fields of pediatric pathology, forensic pathology, and pediatrics came together to revise the definition of SIDS. This became known as the San Diego definition and is the most current working definition of the disease. The general definition states that SIDS is "the sudden unexpected death of a previously healthy infant during sleep that remains unexplained after a review of clinical history, and a thorough case investigation including complete autopsy and death scene investigation." ${ }^{\prime 6}$ This definition is more specific, inclusive, and allows for more consistency in diagnosis. There were also different categories for diagnosis depending on autopsy findings, which allowed the diagnosis to be stratified. The stratification of the diagnosis allowed cases to be more precisely monitored by public health officials and formalize practices among pathologists of separating cases by the degree of certainty of SIDS as cause of death. It would also reduce diagnostic confusion and identify cases that previously would have been excluded incorrectly from SIDS diagnoses. ${ }^{6}$ In 2007, Bajanowski et al designed a study using standard autopsy protocol to classify cases of SIDS. ${ }^{7}$ They defined diagnostic criteria for Category I SIDS that included cases with no significant pathologic changes on complete autopsy. Category II SIDS included cases with minor changes that may be associated with disease or functional disturbance but could not explain death. They also felt that the diagnosis should not be left up to one person, but that the information should be shared at a multidisciplinary meeting and the case be discussed completely before the diagnosis was finalized. ${ }^{7}$
When defining SIDS one must also consider the triple risk hypothesis. ${ }^{8,9}$ Bergman wrote in 1970 that SIDS did not depend on any single characteristic, but an interaction of risk factors with variable probabilities. ${ }^{10}$ Wedgwood refined this in 1972 with the triple risk hypothesis, consisting of general vulnerability, age specific risks, and precipitating factors. ${ }^{8,9}$ In 1994, Filiano and Kinney further refined the triple risk model, suggesting that three different conditions be met. The first condition is vulnerability in the infant, the second is a critical developmental period, and the third is an exogenous or outside stressor. ${ }^{11}$ According to this hypothesis, SUID can only occur when all three conditions are present and therefore does not occur in "normal" infants but only in vulnerable infants with an underlying abnormality. ${ }^{12}$

\section{Epidemiology}

Since the 1960s there has been a decrease in the number of SIDS deaths, initially referred to as crib/cot deaths. ${ }^{13}$ From 1960-1972, as recognition of sudden infant death as a syndrome was becoming known, the frequency of occurrence was decreasing. In 1960, there were 1.22 and 4.41 deaths per 1000 live births of white and black infants in Philadelphia, PA, respectively. This decreased to 0.61 and 3.64 by $1972 .{ }^{13}$ A similar decrease in SIDS was also noted in Australia from 1980-2002. Australia introduced their Reduce the Risks campaign in 1991, which was associated with a decrease in SIDS deaths from 0.965 per 1000 live births to 0.515 . They found that the decrease in SIDS was not related to a diagnostic shift or changes in coding systems. ${ }^{14}$

From 1992-1999, the SIDS rate in the US decreased from 1.2 per 1000 live births to 0.67 per 1000 live births. ${ }^{15}$ This decrease has been attributed to the initiation of the Back to Sleep campaign by the American Academy of Pediatrics (AAP) in 1992 and endorsed by the US Public Health Service in 1994. SIDS is currently the third leading cause of infant mortality behind congenital malformations and disorders related to short gestation. ${ }^{16}$ There were 2327 deaths, estimated to be 0.54 deaths per 1000 live births, in 2006. ${ }^{17}$ In 2007, there were 2453 deaths from SIDS, accounting for $8.4 \%$ of infant deaths for that year. This is 0.56 deaths per 1000 live births. ${ }^{16}$ SIDS remained the third leading cause of infant death in 2008 and the leading cause of deaths among infants in the postneonatal period (1-12 months). ${ }^{17}$ There has not been a significant change in the rate of SIDS deaths in the last 10 years. Unfortunately, there was an increase in the number of deaths attributed to SIDS in the US in 2009, continuing it as the number one cause of postneonatal death at $22 \%$ of deaths in that age group. Congenital malformations and disorders related to short ges- 
tation contributed to a higher number of actual deaths if the neonatal age group was also considered. ${ }^{18}$ The true incidence of SIDS may not be known. This is related to a number of factors including the vague definition and diagnostic criteria, leading to diagnostic shifts and the use of other diagnoses such as accidental suffocation, positional accidental asphyxia, and indeterminate cause. ${ }^{15}$ Deaths in the US from 2005-2008 show increased use of suffocation or undetermined cause of death for infants found in a nonideal sleep environment. ${ }^{19}$ The evolving definition of SIDS and the more recent addition of unclassified sudden infant death to the definition of $\operatorname{SIDS}^{6}$ may allow better classification of the disease moving forward and hopefully decrease any misclassification in the future. As more is learned about the risk factors and genetic factors predisposing to this syndrome, it may be discovered that some deaths originally attributed to SIDS were caused by disease processes that were unknown at the time of diagnosis. Eventually this diagnosis may no longer exist. ${ }^{20}$

\section{Risk factors}

A number of risk factors associated with SIDS have been identified. If the triple risk hypothesis is followed, there are two categories of risk factors to consider: the intrinsic risk factors causing the vulnerability of the infants and the extrinsic factors related to the precipitating event. ${ }^{21}$ Several genes have been identified that are associated with increased risk of SUID, but there is no single cause. ${ }^{22}$ Investigations into the neurodevelopment of the brain and respiratory centers have focused on genes that might be associated with making an infant more vulnerable to SIDS. ${ }^{23}$ Other inherited disorders associated with cardiovascular disorders and metabolic disorders have also been sought as an explanation of SIDS. The more information there is about specific genetic risk factors, however, the more difficult it becomes to pin a specific etiology to SIDS. Thus, the original description of the syndrome as multifactoral appears appropriate. ${ }^{22}$

\section{Intrinsic risk factors}

Male gender is an intrinsic risk factor. Low birth weight and prematurity both contribute to increased risk of death from SIDS, ${ }^{24-26}$ as do small for gestational age infants. ${ }^{27}$

Included in the intrinsic risk factors are genetic polymorphisms that can lead to altered arousal, brainstem dysfunction, cardiac disorders, and metabolic alterations associated with increased risk for sudden and unexplained death. One of the most studied alterations is that of the 5HT system, which integrates several autonomic functions such as gasping, ventilation, thermoregulation, response to carbon dioxide and oxygen, and arousal from sleep. ${ }^{28-35}$ There are two known regions in the serotonin transporter gene (5HTT) known to alter its bioavailability. ${ }^{36}$ Most studies show an association with long $\mathrm{L}$ and XL alleles of the 5HTT promoter and SIDS. ${ }^{22}$ Filonzi et al showed an increase in L/L genotype in idiopathic apparent life threatening events and SIDS cases. They hypothesized that this marker may be a valuable tracer of SIDS risk in a subset of apparent life threatening event infants. ${ }^{37}$ Two changes of the 5HTT gene have increased prevalence in SIDS cases: changes in the 5HTT linked promoter region and changes in the number of variable tandem repeats of intron 2. Long alleles of the promoter region were found more frequently in SIDS cases with homozygous L/L having the greatest frequency. Of note, no cases were found to have $\mathrm{S} / \mathrm{S}$ genotype. Intron 2 alterations are important because of their functional role in gene expression. Alleles 10 and 12 were evaluated and noted to have increased frequency of SIDS in 10/12 and 12/12 infants. However, the numbers of 10 and 12 alleles were the same in both SIDS and control groups. ${ }^{38}$ The long alleles are thought to be related to SIDS either through downregulation of presynaptic autoreceptors or through altered development of the brainstem. ${ }^{38}$

Monoamine oxidase $\mathrm{A}$ is a mitochondrial enzyme that inactivates serotonin and noradrenalin in the human brainstem. It regulates serotoninergic signals through catabolism of vesicular serotonin in the presynaptic region. ${ }^{37}$ In 2008, Nonnis Marzano et al was not able to show statistical significance of different genotypes with increased repeats, specifically the three-repeat allele, in SIDS cases. ${ }^{38}$ Previous gene expression studies showed that the number of repeats in the gene is related to transcriptional efficiency of the gene. ${ }^{39}$ Later studies showed a highly significant association of pooled low expressing $M A O A$ alleles (two and three repeats) and SIDS. ${ }^{40,41}$ Interestingly, 3.5- and four-repeat alleles were noted to be protective. ${ }^{42}$ This data was only statistically significant in male infants and was hypothesized to be because it was the first $\mathrm{X}$ chromosomal polymorphism associated with SIDS. ${ }^{42}$ However, there were also studies that did not show this association. ${ }^{43}$

Another gene associated with catecholamine synthesis and regulation of respiration is tyrosine hydroxylase. Allele 9.3 on this gene is associated with noradrenalin production. Courts and Madea and Klintschar et al independently were able to show an association between this gene allele and SUID. ${ }^{44,45}$

Many SIDS victims have an activated immune system at the time of death, which may make them more vulnerable. ${ }^{46}$ Genes related to immune function have been evaluated 
including genes encoding complement components $\mathrm{C} 4 \mathrm{~A}$ and $\mathrm{C} 4 \mathrm{~B}$, genes encoding interleukin-6 and interleukin-10 as well as tumor necrosis factor- $\alpha$. Partial deletions of the complement C4 gene have been associated with SIDS. ${ }^{47}$ Studies that investigated alterations of the gene promoter for interleukin-10 have been inconclusive. ${ }^{48,49}$ Most of these studies show alleles that have increased frequency in SIDS, but significance is still unknown. One hypothesis is that an impaired complement system together with acute infection may lead to SIDS. Another hypothesis is adenosine triphosphate depletion as a result of dysfunctional mitochondrial metabolism from mutations in mitochondrial DNA. There are alterations noted with single cases, but no recurrent mutation is known at this time. ${ }^{22}$

Carnitine palmitoyltransferase- 1 is an important enzyme in the mitochondrial oxidation of long chain fatty acids and in regulation of $\beta$-oxidation in response to systemic signals of energy availability. ${ }^{50}$ Absence of this enzyme can lead to a hypoketotic, hypoglycemic encephalopathy and sudden death. ${ }^{51}$ A variant of this enzyme (p.P479L), which has decreased activity, has a higher prevalence in aboriginal communities across North America including Greenland, Nunavut, Northwest Territories, and Alaska. Homozygotes for this variant were over represented in SUID cases in British Colombia in 1999-2009..$^{50}$

There have also been studies related to genetic alterations causing a physiologic effect such as long QT syndrome. ${ }^{52}$ Long QT syndrome can be caused by mutations of genes encoding ion channels such as: KVLQT1, HERG, SNC5A, $K C N E 1$, and KCNE2. ${ }^{53}$ Animal studies have shown that hypoxia can lead to downregulation of cardiac ion channels. In a mouse model it was demonstrated that maturation of the cardiac conduction system is oxygen dependent. ${ }^{54}$ Elevation of cardiac hypoxia signaling led to arrhythmia and death in mouse pups. Neary et al hypothesized that hypoxia could be an important trigger for prolonged QT and subsequent death by downregulation of sodium, potassium, and calcium channels in the myocardium. ${ }^{54}$ There have also been many studies showing genes associated with alterations in SCN5A and SIDS. ${ }^{53}$ Mutations in KCNJ2 were also noted to be more frequent in SIDS cases than controls. ${ }^{22}$

Some metabolic conditions have been hypothesized to be related to SUID. Medium chain acyl-CoA dehydrogenase deficiency is the most common inherited disorder of fatty acid metabolism and is very frequently associated with a specific mutation (A985G) of exon 11 on the medium chain acyl-CoA dehydrogenase gene. ${ }^{55}$ Several studies failed to find an association with increased frequency of SUID. ${ }^{56,57}$
The studies did show the importance of evaluating for fatty oxidation disorders as the cause of death in suspected SIDS deaths, but if found these deaths would not be classified as SIDS. ${ }^{20}$

The newest studies are looking at factors related to development and function of the respiratory and autonomic centers of the brain. Bejjani et al hypothesized that the apoptosis in SIDS dorsal motor nucleus of the vagus is initiated by a hypoxic stimulus with resultant intermittent hypoxia being caused by several neurotransmitter receptor systems. ${ }^{58}$ Previous studies showed increased apoptosis, delayed maturation of neurons, and decreased number of neurons in this region of the brain. They incorporate this and many of the above mentioned genes and receptor systems (5HT receptors, tyrosine hydroxylase, acetylcholine and its receptors). Their proposed mechanism for SIDS is based on decreased neuronal growth, increased programmed cell death, and changes at the neurochemical level within the dorsal motor nucleus of the vagus. ${ }^{58}$

One of the main sites of central chemoreception and respirator drive is the retrotrapezoid nucleus, a cluster of neurons on the ventral surface of the medulla oblongata. Cat studies have allowed researchers to identify the location of this center. ${ }^{59}$ In humans, it is suspected to be at the pontomedullary junction ventral to the facial nucleus and lateral to the superior olivary nucleus. ${ }^{60}$ It is known that increased acid in this area stimulates ventilation and that lesions or inhibition of neurons in this area leads to decreased breathing. Lavezzi et al hypothesized that developmental abnormalities of this region played a role in SIDS. They were able to show immature neurons or hypoplasia/agenesis and decreased expression for $P H O X 2 B$ in this region in SIDS cases, and propose a potential mutation in $P H O X 2 B$ that has not yet been identified. ${ }^{61}$

\section{Extrinsic factors}

There are many proposed mechanisms and genetic alterations that may predispose an infant to SIDS, but without a trigger death will not occur. ${ }^{8}$ After the initiation of the Back to Sleep campaign in 1992, there has been a decrease in SIDS deaths in the US. It was initially noticed in Hong Kong in 1985 that few infant deaths were attributed to SIDS. It was custom for infants in that area to be placed supine for sleep. ${ }^{62}$ European and Australian countries started having parents place infants supine for sleep in 1987-1992, which was followed by Canada in 1993 and finally the US in 1994. Infants have decreased slow wave sleep when placed supine as well as a decreased arousal threshold. After the initiation of this sleep- 
ing practice in the US there was a notable reduction in deaths attributed to SIDS. However, there were initial concerns that this practice might be associated with delayed milestones and social development. ${ }^{63}$ The AAP then implemented "tummy time" recommendations while awake and head position changes for sleep to prevent positional plagiocephaly. The degree of developmental delay is related to the amount of time spent in the prone position while awake. ${ }^{63}$ The initial AAP recommendation in 1992 to place infants on the back or side was changed to supine only in 1996 as side sleeping was associated with increased risk of SIDS.

Other sleep-associated risk factors are shared sleeping environment and presence of soft bedding. An examination of infant deaths in the US from 2005-2008 found that those classified as suffocation or undetermined were more likely to be found in a sleep environment not recommended for infant sleep such as shared sleep environment, soft bedding present in crib, infant sleeping on adult bed or other soft surface, and prone sleep position. ${ }^{19}$ Although these risk factors for SIDS were initially described before it was known that soft bed surfaces and prone sleep position could lead to suffocation, these remain easily modifiable factors to prevent sudden infant death whether diagnosed as SIDS (diagnosis needs to remain unidentified) or other causes.

A firm sleep surface is recommended and should be devoid of soft bedding (pillows, toys, blankets) to prevent SIDS and suffocation. ${ }^{64,65}$ The mattress should have a fitted sheet and should be the appropriate size for the crib. Infants should not sleep in an adult bed or with other persons especially if they have taken medication that increases fatigue, have consumed alcohol, smoked, or are excessively tired. It is recommended in the US that all infants share a room with parents, but not share a bed. In breastfed infants, this may also facilitate breastfeeding. If the infant is brought to the adult bed for feeding, he or she should be returned to the crib prior to the parent falling back to sleep. ${ }^{64,65}$ In Australia and the UK, it is acknowledged that many parents choose to bed share for cultural or other reasons and a risk minimization approach is used. It is recommended that an adult bed with some safety measures is safer than falling asleep on the sofa or in an armchair. ${ }^{66}$

Infants that participate in bed sharing are at increased risk for SIDS in certain circumstances ${ }^{67}$ Healthy infants with no other known SIDS risk factors experience more oxygen desaturation preceded by central apnea and rebreathing during bed sharing experiences. This may be related to the infant being in a warmer microenvironment. Oxygen desaturation is generally mild and associated with warmer temperature, but healthy infants respond appropriately to these stressors. ${ }^{67}$ There is concern that more vulnerable infants may not be able to respond to these extrinsic stressors.

Temperature control is also an important risk factor for SIDS. Overheating is an independently associated risk factor for sudden infant death. ${ }^{66}$ Infants who died of SUID from October 1988 to September 1990 in Tasmania, Australia were evaluated for room temperature and thermal insulation. Ponsonby et al found that infants who died of SIDS were overdressed for the room temperature compared with control infants and more often in the prone position. Prone positioning can reduce heat loss by decreased body surface area available for heat loss. There could also be decreased respiratory heat loss caused by facial obstruction in the prone position or when extraneous bedding is found at the death scene. ${ }^{68}$ There was a small study $(\mathrm{N}=28)$ of genes encoding heat shock proteins that revealed a significant association between the loss of a fragment of hsp60 and SIDS. ${ }^{20,69}$

The use of soft bedding, pillows, and specifically infant sleep positioners is not recommended. ${ }^{70}$ Infant sleep positioners have been reported to be present in the bed of some infants who died of unintentional suffocation. Although the US Food and Drug Administration has approved some devices for management of reflux or plagiocephaly, most devices are marketed to the general public to prevent SIDS and improve infant sleep comfort. These devices can be dangerous and lead to suffocation of the infant and are therefore not recommended by the AAP. ${ }^{64,65,70}$

It is well known that breastfeeding is the preferred nutrition for most infants. It helps to improve their immune systems and decreases incidence and frequency of gastrointestinal and respiratory illnesses in the first year of life. ${ }^{71}$ There are studies that show improved cognitive function in breastfed infants as well as improved maternal infant bonding. ${ }^{72}$ There may also be decreased incidence of atopic and inflammatory bowel diseases as an adult. ${ }^{73,74}$ In 1987, the National SIDS Council of Australia held a meeting to review evidence in relation to risk factors for SIDS. In 1991, they started the Reducing the Risks of SIDS campaign, in which breastfeeding was included as a protective factor. In 1997, the council removed breastfeeding from the official recommendations as the evidence was inconclusive after correcting for other well-known risk factors. But in 2012, breastfeeding as a protective factor was again added to the SIDS and Kids Safe Sleeping national public health campaign in Australia. ${ }^{75}$ The AAP Task Force on SIDS has also included breastfeeding as a risk reduction strategy for SIDS in its most recent recommendations. ${ }^{64,65}$ 
Currently, the International Society for the Study and Prevention of Infant Death, much of Europe, and Australia differ from the AAP in regard to pacifier use. The AAP recommends using a pacifier, ${ }^{64}$ whereas the other organizations recommend that they should be used only if the parents choose to use a pacifier and that pacifier use should be delayed 4-6 weeks until breastfeeding is well established. ${ }^{75}$ All of the organizations agree that pacifiers should not be reinserted after the infant falls asleep and should be delayed until breastfeeding is well established (AAP guidelines recommend 3-4 weeks as opposed to 4-6 weeks). ${ }^{65,75}$

Additionally, it is known that prenatal tobacco exposure increases an infant's vulnerability. Fifer et al reported that prenatal smoking and or alcohol exposure is associated with alterations in autonomic control during sleep in the first few days of life. ${ }^{76}$ Maternal tobacco use was associated with decreased beat to beat variability in quiet sleep of Native Americans of the Northern Plains. Heart rate variability was not altered during periods of movement in active sleep but the average heart rate was lower. ${ }^{76}$ Smoke-exposed infants also have decreased progression from subcortical activation to cortical arousal at 2-4 weeks and 5-6 months post gestational age. Exposure to tobacco in these infants impaired arousal processes to trigeminal stimulation and is thought to be a risk factor for SUID. The effect was dependent on the amount of urinary cotinine, a nicotine metabolite, measured at 2-3 months of age. This suggests that smoking is not only a risk factor in utero, but also from postbirth exposure. ${ }^{77}$ Kinney hypothesizes that nicotine in maternal cigarette smoke may bind to receptors on 5HT neurons in the fetal medulla and adversely affect development and function. This may be directly toxic to $5 \mathrm{HT}$ metabolism. Smoking during pregnancy is associated with a $41 \%$ reduction in $5 \mathrm{HT}$ binding in the human arcuate nucleus in the postnatal period. ${ }^{23}$

Given the vulnerabilities and environmental risk factors that are known to be associated with SUID, it is small wonder that infant deaths are still attributed to this syndrome. Nevertheless, given that environmental risk factors can be modified, why have SIDS rates remained relatively unchanged over the last 10 years? Barriers to appropriate sleep conditions may be one factor. Poets et al described increased desaturation episodes when sleeping supine. ${ }^{78}$ Parental concerns that the infant will choke may be one reason that infants are still placed prone or in a side lying position for sleep. The observation that there has not been an increase in mortality attributed to aspiration in association with an increase in the prevalence of supine sleep positioning should serve to diminish that concern. ${ }^{79}$
It cannot be overlooked that in the US SIDS disproportionately affects infants and families of African Americans, Native Americans, and Alaskan Natives. ${ }^{80}$ The higher prevalence of young, single mothers with low educational attainment in the African American population contributes greatly to their higher risk of SIDS. Also, Native American and Alaskan Native infants have a higher incidence of exposure to smoke and bed sharing, while black infants are more likely to be placed in a prone position for sleep. ${ }^{81}$

Parent beliefs about SIDS play an important role in how they take care of their infants. Many parents do not understand the link between pediatrician recommendations and the death of their infants. They feel that vigilance is the most effective prevention for sudden death. ${ }^{44}$ Some families cannot follow the recommendations for financial or space reasons. Others may have mothers that cannot breastfeed for medical or other reasons. More research is needed to determine the best alternative for families that want to follow the guidelines but physically cannot do so. And more importantly, increased awareness of SIDS and education on prevention techniques needs to be provided to the public. Increased attention should be in areas of higher incidence and populations with increased risk such as African American and Native American communities. Given the current knowledge of risk factors for SIDS, extrinsic/environmental factors account for the largest proportion of SIDS deaths and offer the most modifiable factors to reduce the risk for sudden infant death.

\section{Conclusion}

Are we any closer to identifying which infant will be affected? It is understood that SIDS is a multifactoral process. A great deal has been learned about the risk factors that predispose vulnerable children to death during infancy in the last 43 years. Children at increased risk are able to be better identified, but not which children will succumb to SIDS. It is known that modification of extrinsic and environmental risk factors is the best way to prevent sudden infant death. Supine sleep has had a significant impact on prevention of SIDS, but a safe sleep environment is more important than just supine positioning. The AAP remains dedicated to the promotion of a safe sleep environment for all infants and have renamed the campaign Safe to Sleep. The campaign promotes educating parents on a safe sleep environment from birth and providing consistent reminders at all well child visits until 1 year of age. Thus, attention to modifying the extrinsic risk factors for SIDS through education of the most vulnerable populations appears to be the best strategy currently available to continue to chip away at the occurrence of this puzzling syndrome. 


\section{Disclosure}

The authors report no conflicts of interest in this work.

\section{References}

1. Beckwith JB. Defining the sudden infant death syndrome. Arch Pediatr Adolesc Med. 2003;157(3):286-290.

2. Beckwith JB. The sudden infant death syndrome. Curr Probl Pediatr. 1973;3(8):1-36.

3. Peterson DR. Evolution of epidemiology of sudden infant death syndrome. Epidemiol Rev. 1980;2:97-112.

4. Willinger M, James LS, Catz C. Defining the sudden infant death syndrome (SIDS): deliberations of an expert panel convened by the National Institute of Child Health and Human Development. Pediatr Pathol. 1991;11(5):677-684.

5. Beckwith JB. Discussion of terminology and definition of the sudden infant death syndrome. In: Bergman AB, Beckwith JB, Ray CG, editors. Sudden Infant Death Syndrome: Proceedings of the Second International Conference on the Causes of Sudden Death in Infants. Seattle, WA: University of Washington Press; 1970:14-22.

6. Krous HF, Beckwith JB, Byard RW, et al. Sudden infant death syndrome and unclassified sudden infant deaths: a definitional and diagnostic approach. Pediatrics. 2004;114(1):234-238.

7. Bajanowski T, Vege A, Byard RW, et al. Sudden infant death syndrome (SIDS)-standardized investigations and classification: recommendations. Forensic Sci Int. 2007;165(2-3):129-143.

8. Guntheroth WG, Spiers PS. The triple risk hypotheses in sudden infant death syndrome. Pediatrics. 2002;110(5):e64.

9. Wedgwood RJ. Review of USA experience. In: Camps FE, Carpenter RG, editors. Sudden and Unexplained Death in Infancy (Cot Deaths). Bristol: John Wright; 1972:28.

10. Bergman AB. Synthesis. In: Bergman AB, Beckwith JD, Ray CG, editors. Sudden Infant Death Syndrome: Proceedings of the Second International Conference on the Causes of Sudden Death in Infants. Seattle, WA: University of Washington Press; 1970:210-211.

11. Filiano JJ, Kinney HC. A perspective on neuropathologic findings in victims of the sudden infant death syndrome: the triple-risk model. Biol Neonate. 1994;65(3-4):194-197.

12. Kinney HC, Thach BT. The sudden infant death syndrome. $N$ Eng $J$ Med. 2009;361(8):795-805.

13. Valdes-Dapena M, McGovern JA, Birle LJ, Auerbach VH. Changes in annual incidence rates of sudden unexpected deaths among infants in Philadelphia, 1960-1972. J Pediatr. 1974;84(5):776-777.

14. Tursan d'Espaignet E, Bulsara M, Wolfenden L, Byard RW, Stanley FJ. Trends in sudden infant death syndrome in Australia from 1980 to 2002. Forensic Sci Med Pathol. 2008;4(2):83-90.

15. Malloy MH, MacDorman M. Changes in the classification of sudden unexpected infant deaths: United States, 1992-2001. Pediatrics. 2005;115(5): 1247-1253.

16. Xu J, Kochanek KD, Murphy SL, Tejada-Vera B. Death: final data for 2007. Natl Vital Stat Rep. 2010;58(19):1-34.

17. Mathews TJ, MacDorman MF. Infant mortality statistics from the 2006 period: linked birth/death data set. Natl Vital Stat Rep. 2010;58(17): $1-32$.

18. Heron M. Deaths: leading causes for 2009. Natl Vital Stat Rep. 2012;61(7):1-96.

19. Schnitzer PG, Covington TM, Dykstra HK. Sudden unexpected infant deaths: sleep environment and circumstances. Am J Public Health. 2012;120:1204-1212.

20. Opdal SH, Rognum TO. The sudden infant death gene: does it exist? Pediatrics. 2004;114(4):e506-e512.

21. Trachtenberg FL, Haas EA, Kinney HC, Stanley C, Krous HF. Risk factor changes for sudden infant death syndrome after initiation of Back-to-Sleep campaign. Pediatrics. 2012;129(4):630-638.

22. Courts C, Madea B. Genetics of the sudden infant death syndrome. Forensic Sci Int. 2010;203(1-3):25-33.
23. Kinney HC, Broadbelt KG, Haynes RL, Rognum IJ, Paterson DS. The serotonergic anatomy of the developing human medulla oblongata: implications for pediatric disorders of homeostasis. J Chem Neuroanat. 2011;41(4):182-199.

24. Malloy MH, Freeman DH Jr. Birth weight- and gestational age-specific sudden infant death syndrome mortality: United States, 1991 versus 1995. Pediatrics. 2000;105(6):1227-1231.

25. Malloy MH, Hoffman HJ. Prematurity, sudden infant death syndrome, and age of death. Pediatrics. 1995;96(3 Pt 1):464-471.

26. Malloy MH. Size for gestational age at birth: impact on risk for sudden infant death and other causes of death, USA 2002. Arch Dis Child Fetal Neonatal Ed. 2007;92(6):F473-F478.

27. Altman M, Edstedt Bonamy AK, Wikstrom AK, Cnattingius S. Causespecific infant mortality in a population-based Swedish study of term and post-term births: the contribution of gestational age and birth weight. BMJ Open. 2012;2(4):e001152.

28. Tryba AK, Pena F, Ramirez JM. Gasping activity in vitro: a rhythm dependent on 5-HT2A receptors. J Neurosci. 2006;26(10):2623-2634.

29. St-John WM, Leiter JC. Maintenance of gasping and restoration of eupnea after hypoxia is impaired following blockers of alpha1adrenergic receptors and serotonin 5-HT2 receptors. J Appl Physiol. 2008;104(3):665-673.

30. Audero E, Coppi E, Mlinar B, et al. Sporadic autonomic dysregulation and death associated with excessive serotonin autoinhibition. Science. 2008;321(5885):130-133.

31. Van Norstrand DW, Tester DJ, Ackerman MJ. Overrepresentation of the proarrhythmic, sudden death predisposing sodium channel polymorphism S11034 in a population-based cohort of AfricanAmerican sudden infant death syndrome. Heart Rhythm. 2008;5(5): 712-715.

32. Bradley SR, Pieribone VA, Wang W, Severson CA, Jacobs RA, Richardson GB. Chemosensitive serotonergic neurons are closely associated with large medullary arteries. Nat Neurosci. 2002;5(5): 401-402.

33. Penatti EM, Berniker AV, Kereshi B, et al. Ventilatory response to hypercapnia and hypoxia after extensive lesion of medullary serotonergic neurons in newborn conscious piglets. J Appl Physiol. 2006;101(4): $1177-1188$.

34. Darnall RA, Harris MB, Gill WH, Hoffman JM, Brown JW, Niblock MM. Inhibition of serotonergic neurons in the nucleus paragigantocellularis lateralis fragments sleep and decreases rapid eye movement sleep in piglet: implications for sudden infant death syndrome. J Neurosci. 2005;25(36):8322-8332.

35. Feldman JL, Mitchell GS, Nattie EE. Breathing: rhythmicity, plasticity, chemosensitivity. Annu Rev Neurosci. 2003;26:239-266.

36. Heils A, Teufel A, Petris S, et al. Allelic variation of human serotonin transporter gene expression. J Neurochem. 1996;66(6):2621-2624.

37. Filonzi L, Magnani C, Nosetti L, et al. Serotonin transporter role in identifying similarities between SIDS and idiopathic ALTE. Pediatrics. 2012;130(1):e138-e144.

38. Nonnis Marzano F, Maldini M, Filonzi L, et al. Genes regulating the serotonin metabolic pathway in the brain stem and their role in the etiopathogenesis of the sudden infant death syndrome. Genomics. 2008;91(6):485-491.

39. Denney RM, Koch H, Craig IW. Association between monoamine oxidase A activity in human male skin fibroblasts and genotype of the MAOA promoter-associated variable number tandem repeat. Hum Genet. 1999;105(6):542-551.

40. Weese-Mayer DE, Berry-Kravus EM, Maher BS, Silvestri JM, Curran ME, Marazita ML. Sudden infant death syndrome: association with a promoter polymorphism of the serotonin transporter gene. Am J Med Genet A. 2003;117A(3):268-274.

41. Opdal SH, Vege A, Rognum TO. Serotonin transporter gene variation in sudden infant death syndrome. Acta Paediatr. 2008;97(7): 861-865.

42. Klintschar M, Heimbold C. Association between a functional polymorphism in the MAOA gene and sudden infant death syndrome. Pediatrics. 2012;129(3):e756-e 761. 
43. Paterson DS, Rivera KD, Broadbelt KG, et al. Lack of association of the serotonin transporter polymorphism with the sudden infant death syndrome in the San Diego dataset. Pediatr Res. 2010;68(5): 409-413.

44. Courts C, Madea B. Significant association of TH01 allele 9.3 and SIDS. J Forensic Sci. 2011;56(2):415-417.

45. Klintschar M, Reichenpfader B, Saternus KS. A functional polymorphism in the tyrosine hydroxylase gene indicates a role of noradrenalinergic signaling in sudden infant death syndrome. J Pediatr. 2008;153(2):190-193.

46. Arnestad M, Andersen M, Vege A, Rognum TO. Changes in the epidemiological pattern of sudden infant death syndrome in southeast Norway, 1984-1998: implications for future prevention and research. Arch Dis Child. 2001;85(2):108-115.

47. Campbell RD, Dunham I, Kendall E, Sargent CA. Polymorphism of the human complement component C4. Exp Clin Immunogenet. 1990;7(1):69-84.

48. Eskdale J, Keijsers V, Huizinga T, Gallagher G. Microsatellite alleles and single nucleotide polymorphisms (SNP) combine to form four major halotype families at the human interleukin-10 (IL10) locus. Genes Immun. 1999;1(2):151-155.

49. Opdal SH, Opstad A, Vege A, Rognum TO. IL-10 gene polymorphisms are associated with infectious cause of sudden infant death. Hum Immunol. 2003;64(12):1183-1189.

50. Sinclair GB, Collins S, Popescu O, McFadden D, Arbour L, Vallance HD. Carnitine palmitoyltransferase I and sudden unexpected infant death in British Columbia First Nations. Pediatrics. 2012;130(5): e1162-e1169.

51. Bonnefont JP, Djouadi F, Prip-Buus C, Gobin S, Munnich A, Bastin J. Carnitine palmitoyltransferases 1 and 2: biochemical, molecular and medical aspects. Mol Aspects Med. 2004;25(5-6):495-520.

52. Schwartz PJ, Stramba-Badiale M, Segantini A, et al. Prolongation of the QT interval and the sudden infant death syndrome. N Engl J Med. 1998;338(24):1709-1714.

53. Anestad M, Crotti L, Rognum TO, et al. Prevalence of the long-QT syndrome gene variants in sudden infant death syndrome. Circulation. 2007;115(3):361-367.

54. Neary MT, Mohun TJ, Breckenridge RA. A mouse model to study the link between hypoxia, long QT interval and sudden infant death syndrome. Dis Model Mech. November 16, 2012. [Epub ahead of print.]

55. Andresen BS, Bross P, Jensen TG, et al. Molecular diagnosis and characterization of medium-chain acyl-CoA dehydrogenase deficiency. Scand J Clin Lab Invest Suppl. 1995;220:9-25.

56. Penzien JM, Molz G, Wiesmann CH, Colombo JP, Buhlmann R, Wermuth B. Medium-chain acyl-CoA dehydrogenase deficiency does not correlate with apparent life-threatening events and the sudden infant death syndrome: results from phenylpropionate loading tests and DNA analysis. Eur J Pediatr. 1994;153(5):352-357.

57. Santer R, Gregersen N, Tanaka K, Hinck-Kneip C, Krawinkel M, Schaub J. The prevalence of the G985 allele of medium-chain acyl-CoA dehydrogenase deficiency among sudden infant death victims and healthy newborns in northern Germany. Eur J Pediatr. 1995;154(6):497.

58. Bejjani C, Maachaalani R, Waters KA. The dorsal motor nucleus of the vagus (DMNV) in sudden infant death syndrome (SIDS): pathways leading to apoptosis. Respir Physiol Neurobiol. 2013;185(2):203-210.

59. Smith JC, Morrison DE, Ellenberger HH, Otto MR, Feldman JL. Brainstem projections to the major respiratory neuron populations in the medulla of the cat. J Comp Neurol. 1989;281(1):69-96.

60. Rudzinski E, Kapur RP. PHOX2B immunolocalization of the candidate human retrotrapezoid nucleus. Pediatr Dev Pathol. 2010;13(4): 291-299.

61. Lavezzi AM, Weese-Mayer DE, Yu MY, et al. Developmental alterations of the respiratory human retrotrapezoid nucleus in sudden unexplained fetal and infant death. Auton Neurosci. 2012;170(1-2):12-19.
62. Davies DP. Cot death in Hong Kong: a rare problem? Lancet. 1985; 2(8468):1346-1349.

63. Majnemer A, Barr RG. Influence of supine sleep positioning on early motor milestone acquisition. Dev Med Child Neurol. 2005;47(6): 370-376.

64. Moon RY; Task Force on Sudden Infant Death Syndrome. Technical report: SIDS and other sleep-related infant deaths: expansion of recommendations for a safe infant sleeping environment. Pediatrics. 2011;128(5):e1341-e1376.

65. Moon RY; Taskforce on Sudden Infant Death Syndrome. Policy statement: SIDS and other sleep-related infant deaths: expansion of recommendations for a safe infant sleeping environment. Pediatrics. 2011;128(5):1030-1039.

66. Blair PS, Sidebotham P, Berry PJ, Evans M, Fleming PJ. Major epidemiological changes in sudden infant death syndrome: a 20-year population-based study in the UK. Lancet. 2006;367(9507):314-319.

67. Baddock SA, Galland BC, Bolton DP, Williams SM, Taylor BJ. Hypoxic and hypercapnic events in young infants during bed-sharing. Pediatrics. 2012;130(2):237-244.

68. Ponsonby AL, Dwyer T, Gibbons LE, Cochrane JA, Jones ME, McCall MJ. Thermal environment and sudden infant death syndrome: case-control study. BMJ. 1992;304(6822):277-282.

69. Rahim RA, Boyd PA, Ainslie Patrick WJ, Burdon RH. Human heat shock protein gene polymorphisms and sudden infant death syndrome. Arch Dis Child. 1996;75(5):451-452.

70. Centers for Disease Control and Prevention. Suffocation deaths associated with use of infant sleep positioners - United States, 1997-2011. MMWR Morb Mortal Wkly Rep. 2012;61(46):933-937.

71. Ladomenou F, Moschandreas J, Kafatos A, Tselentis Y, Galanakis E. Protective effect of exclusive breastfeeding against infections during infancy: a prospective study. Arch Dis Child. 2010;95(12):1004-1008.

72. Kramer MS, Chalmers B, Hodnett ED, et al. Promotion of Breastfeeding Intervention Trial (PROBIT): a randomized trial in the Republic of Belarus. JAMA. 2001;285(4):413-420.

73. Horta BL, Bahl R, Martines JC, Victora CG. Evidence on the Longterm Effects of Breastfeeding: Systemic Reviews and Meta Analyses. Geneva: World Health Organization; 2007. Available from: http:// whqlibdoc.who.int/publications/2007/9789241595230_eng.pdf. Accessed February 18, 2013.

74. Barclay AR, Russell RK, Wilson ML, Gilmour WH, Satsangi J, Wilson DC. Systematic review: the role of breast feeding in the development of pediatric inflammatory bowel disease. J Pediatr. 2009;155(3): 421-426.

75. Young J, Watson K, Ellis L, Raven L. Responding to evidence: breastfeed baby if you can - the sixth public health recommendation to reduce the risk of sudden and unexpected death in infancy. Breastfeed Rev. 2012;20(1):7-15

76. Fifer WP, Fingers ST, Youngman M, Gomez-Gribben E, Myers MM. Effects of alcohol and smoking during pregnancy on infant autonomic control. Dev Psychobiol. 2009;51(3):234-242.

77. Richardson HL, Walker AM, Horne RS. Maternal smoking impairs arousal patterns in sleeping infants. Sleep. 2009;32(4):515-521.

78. Poets A, Urschitz MS, Poets CF. Intermittent hypoxia in supine versus side position in term neonates. Pediatr Res. 2009;65(6):654-656.

79. Malloy MH. Trends in postneonatal aspiration deaths and reclassification of sudden infant death syndrome: impact of the "Back to Sleep" program. Pediatrics. 2002;109(4):661-665.

80. MacDorman MF, Mathews TJ. Recent trends in infant mortality in the United States. NCHS Data Brief. 2008;(9):1-8.

81. Hauck FR, Tanabe KO, Moon RY. Racial and ethnic disparities in infant mortality. Semin Perinatol. 2011;35(4):209-220. 
Pediatric Health, Medicine and Therapeutics

Dovepress

\section{Publish your work in this journal}

Pediatric Health, Medicine and Therapeutics is an international, peerreviewed, open access journal publishing original research, reports, editorials, reviews and commentaries. All aspects of health maintenance, preventative measures and disease treatment interventions are addressed within the journal. Practitioners from all disciplines are invited to submit their work as well as healthcare researchers and patient support groups. The manuscript management system is completely online and includes a very quick and fair peer-review system. Visit http://www.dovepress.com/ testimonials.php to read real quotes from published authors.

Submit your manuscript here: http://www.dovepress.com/pediatric-health-medicine-and-therapeutics-journal 